\section{Nuclear cheap?}

SIR-May I comment belatedly on Professor Jeffery's letter on nuclear costs (Nature 23 October, p.674). It is pointless trying to recalculate electricity generation costs on the basis of arbitrary rules. If, as Professor Jeffery believes, capital costs are inadequately reflected, does he propose to recalculate the current costs of coal and its transport in terms of capital expended in the nineteenth century? How does he propose to take account of the fact that if there had been no nuclear contribution the additional fossil fuel supplies would have had to come from expanded output at the marginal and most expensive sources? The costs published by the Central Electricity Generating Board (CEGB) for generation from Magnox nuclear stations and coal and oil fired power stations of similar age and load history, show that on a perfectly proper accountancy basis, including allowance for costs yet to be incurred, the price we would be paying for electricity would be higher now had fossil stations been preferred in the past.

The industry has stressed, however, that this alone is not a guide to future investment, any more than it would be if Magnox fuel costs increased more rapidly than coal and reversed the current cost position. Incidentally Professor Jeffery's projection of fossil fuel prices in terms of the sum of coal and oil prices compounds changes in fuel mix and offsets rising coal prices with the decline in real oil prices following the major price excursion in 1973. It conceals the 60 per cent real increase in coal prices which occurred between 1970 and 1979 .

Fuel cycle costs for advanced gas-cooled reactors or pressurized water reactors are different from Magnox in that they refer to oxide fuels with higher burn up for reprocessing in THORP. Estimated future fuel costs are based in part on the expected cost of this plant. Electricity costs for stations yet to be constructed are calculated in constant money terms on a levelized cost basis by summing expected future discounted expenditures and dividing by expected discounted output. Our calculations, which may differ in detail from those of CEGB, suggest that even if coal costs were held steady and uranium prices allowed to rise (both contrary to present trends) nuclear should retain a small cost advantage.

P.M.S. JONES

UK Atomic Energy Authority, London $S W I, U K$

\section{Biospheric works}

SIR - I have just read your article concerning Unesco in the 6 November issue of Nature. While I shall refrain from commenting upon the overall content of the article - although for instance we do not know here of any "new technological order" which would have been approved by the recent Belgrade session of our General Conference - there is one point in your text which particularly puzzles me. You state that our programme on Man and the Biosphere (MAB) - in which many scientists and institutions actively participate all over the world - is a source of "largely empty generalizations" and that "people and member governments increasingly ask whether it can be worth its cost".
A few years ago I outlined this programme to your readers in a lead article which appeared in Nature of 17th July 1975. The programme was still only emerging from its preparatory phase. It is now fully operational, with close to a thousand very concrete research projects under way in some 75 countries. Around 200 biosphere reserves have been established under the programme in 50 countries. Networks of integrated pilot research, training and demonstration projects have been set up in the humid tropics and in the arid grazing lands. Cities like Rome, Frankfurt or Mexico are being studied as urban systems under MAB. The annual cost of the programme to Unesco is approximately $\$ 2$ million only. This catalytic amount has attracted - mainly from industrialized countries - some $\$ 50$ millions of extrabudgetary support. In the aggregate it is estimated that national commitments to MAB run at about $\$ 200$ millions per year. It would indeed be strange that research organizations would spend such amounts for applied ecological studies leading only to empty generalizations. And everyone present at Belgrade can testify that the programme received enthusiastic support from all governments represented, whether developed or developing.

As a final point, let me indicate that MAB will be 10 years old this year and that we are organizing next October jointly with the International Council of Scientific Unions a conference-exhibit to review the progress of $\mathrm{MAB}$, to evaluate its achievements and shortcomings and to make recommendations for its future. Any constructive criticism which Nature and its readers would wish to make would be most appreciated. But sweeping unsubstantiated statements are of no use in this context.

Unesco, Paris, France

M. BATISSE

\section{More on museums}

SIR - May someone who is not by profession a scientist join in your controversy about "Museum pieces"? For like so many other non-scientists I do have a strong interest here, and that an interest of the kind which surely ought, in the present case, to be overriding. That is to say, I am a devoted museum goer myself, with children who also need the help of museums in their education. What we consumers of museum services are entitled to expect from our national institutions is a clear, vivid, fair and balanced presentation of all available materials. When there is fundamental disagreement on any issue of substance between the best qualified professional experts, then we are entitled to be told that such disagreement exists and what the main points at issue are.

Dr L.B. Halstead has made a very serious charge (Nature 20 November, p.208) that in the Natural History Museum the exhibits of dinosaurs and of fossil man are now presented in terms of a new theory which none of his critics has yet even suggested represents the consensus of the experts. Nor, it would appear, have those responsible for making up these exhibits and compiling the accompanying booklets done anything to explain and to stress that theirs is only one view, and that probably a minority view, among those who are best qualified to judge. 1 would emphasize again that I make no pretensions whatsoever to any such special expertise. But it requires no expertise at all to recognize that Dr Halstead's charges are very serious indeed, and that none of the critics whose letters you have so far published has made any attempt to show that the situation is not in fact as scandalous as Dr Halstead's original letter suggested that it is.

Department of Philosophy, University of Reading, UK

SIR-In response to correspondence from L. B. Halstead (Nature 20 November, p. 208), I feel obligated to point out that while science is generally regarded as the outgrowth of processes of the cerebral cortex, Halstead's criticisms of cladistics seem to emanate more from the anterior pituitary.

First, although phylogenetic systematics (cladism) and the punctuated equilibria mode of evolution are largely complementary in their theoretical structure, at least one articulate spokesman for punctuated equilibrium is not a cladist, and therefore it is incorrect to lump the two schools together.

Next, although I am as firmly convinced of gradualism and evolutionary systematics as anyone, it is academic vigilantism to deny the cladists and punctuationists their day in court. Those views are propounded by extremely competent scholars, whom I perceive to be fundamentally committed to the advancement of our understanding of the history and dynamic processes of life on Earth. This is a different goal (in fact, a directly opposite goal) from that of the creationists, and it is highly inappropriate for Halstead to analogize between their motives.

As for Halstead's innuendo that punctuational evolution is a Communist plot, I confess that I am never quite sure when British people are kidding, but I hope that Halstead was. Gould and Eldredge did spend one page of a thirty-five-page paper (Paleobiology 3, 115; 1977) relating their punctuational model of evolutionary change to the more general views of change espoused by Marx. Halstead's criticisms, however, do not address either the issues or the data; they instead take the form: (1) Marxism is wrong; (2) therefore, everything a Marxist says is wrong. This is obscurantism of a most pernicious sort, and side-steps the critical question of whether or not cladism or a punctuational mode of evolution has anything important to contribute to our understanding of the world.

When I see the maxillary and mandibular remains of the Miocene and Pliocene hominoids, I see (along with Halstead, I suspect) anagenesis, migration, allopatric speciation and gradual genetic divergence without necessary recourse to a punctuational scheme. I do not see, however, how the vituperative essay of Halstead's sheds any new light on any relevant issues. Science should proceed through the critical analysis of ideas and explanations by recourse to the facts at hand: processes of logic and reason. Let us keep our hormones out of it.

Department of Anthropology, JON MARKS University of Arizona, Tucson 